\title{
Adhesion to Tuberculosis Preventive Measures by Health Workers in Diagnostic and Treatment Centers in Douala - Cameroon
}

\section{Cecile Djuikoue}

Université des Montagnes, Bagangte

\section{Alex Ndjip Ndjock}

Department of Health and Applied Sciences, Estuary Academic and Strategic Institute, Irene Wandji

Regional Delegation of Public Health Littoral region, Regional Technical Group for the Fight against Tuberculosis Littoral region,

\section{Willy Yamdeu Tchoukouha}

Université des Montagnes, Bagangte

\section{Frank Nounkeu Kouteu}

Department of Health and Applied Sciences, Estuary Academic and Strategic Institute,

\section{Alice Ketchaji}

HIV / AIDS sub-Directorate, Ministry of Public Health,

\section{Ashu Agbor}

Université des Montagnes, Bagangte

\section{Ernest Tambo}

Université des Montagnes, Bagangte

Benjamin Thumamo Pokam ( $\nabla$ thumamo@yahoo.fr)

Department of Medical Laboratory Science, Faculty of Health Sciences, University of Buea,

\section{Research Article}

Keywords: Tuberculosis, Preventive measures, Health workers, Douala, Cameroon.

Posted Date: January 12th, 2021

DOI: https://doi.org/10.21203/rs.3.rs-139309/v1

License: (1) (1) This work is licensed under a Creative Commons Attribution 4.0 International License. Read Full License 


\title{
ADHESION TO TUBERCULOSIS PREVENTIVE MEASURES BY HEALTH WORKERS IN DIAGNOSTIC AND TREATMENT CENTERS IN DOUALA - CAMEROON
}

\author{
Cecile I. Djuikoue ${ }^{1,4}$, Alex S. Ndjip Ndjock ${ }^{2}$, Irène G. Wandji ${ }^{3}$, Willy D. Yamdeu Tchoukouha ${ }^{1}$, \\ Frank W. Nounkeu Kouteu ${ }^{2}$, Alice Ketchaji ${ }^{5}$, Ashu M. Agbor ${ }^{1}$, Ernest Tambo ${ }^{1,4}$, Benjamin D. \\ Thumamo Pokam ${ }^{6}$
}

*Correspondence: thumamo@yahoo.fr, Department of Medical Laboratory Science, Faculty of Health Sciences, University of Buea, Cameroon.

Full list of author information is available at the end of the article.

\begin{abstract}
Background: Tuberculosis (TB) remains a major health problem in Africa and more particularly in sub-Saharan countries such as Cameroon due to its impact on mortality, morbidity and socio-economic repercussions on the population in general, in this case in big cities like Douala. In 2018, the Littoral region in Cameroon recorded more than 5,000 cases of tuberculosis representing a quarter of the total number of TB patients in in the country. The application of measures to control TB infection and the regular surveillance of tuberculosis disease among health workers and at all levels of the health system constitute a public health priority, not only for health and administrative workers, but also for all users. This study assessed the adherence to preventive measures against TB by health workers of the diagnostic and treatment centers in the city of Douala.
\end{abstract}

Methodology: This is a descriptive cross-sectional study carried out among health workers from 12 TB screening and treatment centers in the city of Douala. It took place from July 20, 2020 to August 15, 2020. The data were collected using an observation grid designed on the basis of the technical guidelines for health professionals 4 th Edition set up by the WHO and contextualized in Cameroon through the technical guidelines for health professionals in Cameroon 2020. The data collected was analyzed using the statistical software Epi Info 7.2.3.1.

Results: The implementation of preventive measures (administrative, environmental and individual) against TB by health workers in the diagnostic and treatment centers in the city of Douala was insufficient with the respective adherence average of $79.16 \%$ for management measures, $71.80 \%$ for environmental measures and $54.76 \%$ for individual protection measures.

Conclusion: The poor implementation of infection control measures in the TB diagnostic and treatment centers in the city of Douala can promote exposure of health workers to Mycobacterium tuberculosis. An institutional effort required to resolve this issue and strengthen TB prevention activities.

Keywords: Tuberculosis; Preventive measures; Health workers; Douala; Cameroon. 


\section{Introduction}

Tuberculosis (TB) is one of the top 10 causes of death in the world. It is also the main cause of deaths related to antimicrobial resistance and the leading cause of death among people living with the Human Immunodeficiency Virus (HIV)/Acquired Immunodeficiency Syndrome (AIDS). In 2019, 10 million people contracted TB, and 1.4 million people died from the disease (of which 208,000 also had the HIV infection), while in 2016, of the same estimated cases, only 6.3 million $(61 \%)$ were detected and put on treatment $[1,2]$. TB is an infectious and contagious disease transmitted through air; with variable clinical signs and caused by the bacteria Mycobacterium tuberculosis. Contamination occurs through infected droplets from the patient's lungs. These fine droplets are produced when the patient coughs or sneezes. These particles inhaled by a healthy subject can reach the pulmonary alveoli and cause TB infection [3]. Infection is more likely to occur when a person is exposed to a patient with pulmonary TB on a daily basis, for example by living or working close to a person with an active disease [4]. Studies in some African countries and other parts of the world have shown that health workers are considered to have a higher risk of infection with Mycobacterium tuberculosis than the general population [5]. It is therefore important to take measures to protect healthcare workers working in a context of the spread of TB. Although these measures have been enacted, their application still remains a major challenge. TB remains a major health problem, especially in Africa and more particularly in sub-Saharan countries [6]. Although several research have been carried out in Cameroon on $\mathrm{TB}[6,7,8,9,10]$, there is however a paucity of information on the implementation of preventive measures against TB by health workers in diagnostic and treatment centers in the country. This study therefore seeks to assess the adherence to preventive measures against TB by the health workers of diagnostic and treatment centers in the city of Douala, the cosmopolitan capital of the Littoral region of the country.

\section{Methods}

A descriptive cross-sectional study was carried out in 12 TB diagnostic and treatment centers in the city of Douala: The Deido District Hospital; The Laquintinie Pneumo-Phtisiology Centre; Cité Sic Integrated Health Centre; Cité des Palmiers District Hospital; Douala General Hospital; Nylon District Hospital; Barcelona dispensary; Miséricorde Dispensary; Bonadiwoto District Medical Centre; New Bell District Hospital; Nkololoun Medical District Centre; Logbaba District Hospital. Data collection took place from July 20, 2020 to August 15, 2020. A qualitative observation grid was used to collect data. The assessment of adherence to preventive measures was made on the basis of the technical guide for health professionals 4th Edition set up by the WHO and contextualized in Cameroon through the technical guide for health professionals Cameroon 2020 [11]. We used the statistical software Epi Info 7.2.3.1 to process the data collected and to design the qualitative observation grid. The authorizations to carry out the study were obtained from various local public health institutions and all the health workers of the Diagnostic and Treatment Centre for Tuberculosis (DTCs) concerned were informed and voluntarily joined the study. 


\section{Results}

\section{Administrative management of DCTs}

Seventy five per cent (9/12) of DTCs the city of Douala early identify TB suspects through the criteria, while 3/12 $(25 \%)$ of these centers do not. Half (6/12) of DTCs separate the suspected or confirmed cases from the other patients while the other half group together all the patients in the same hall. Up to 11 (91\%) of the 12 DTCs favor the administration of outpatient treatment for the first 2 months rather than hospitalization. All the 12 DTCs report diagnosed TB cases through the data collection tools of the health information system such as laboratory registers and / or TB registers (Table 1).

Table 1 Administrative measures used in the studied DTCs in Douala

\begin{tabular}{lcc}
\hline \multicolumn{1}{c}{ Administrative measures in the DTCs } & $\begin{array}{c}\text { Frequency } \\
(\mathrm{n}=12)\end{array}$ & Percentage \\
\hline Notification of cases in the DTCs studied & 12 & 100 \\
Administration of treatment on an outpatient basis rather than in hospitalization & 11 & 91.67 \\
Rapid identification of infectious cases and TB suspects & 9 & 75.00 \\
Physical separation of suspected TB patients and confirmed TB cases & 6 & 50.00 \\
Mean & 79.16 \\
\hline
\end{tabular}

DTCs: Diagnostic and Treatment Centers for Tuberculosis

\section{Environmental control measures in DCTs}

In $10(83.33 \%)$ of the 12 DTCs, the staff follow hygiene rules through covering of the nose and mouth by means of a mask, tissue, a paper handkerchief or with the inner part of the elbow. In the 2/12 (16.67\%) other DTCs, the health workers do not respect the rules relating to cough hygiene. Fifty per cent (6/12) of DTCs have hospital rooms ventilated regularly through the opening of doors and windows. The other half of hospital wards are without windows for some, or with closed doors for others. On one hand, 9 (75\%) of the 12 DTCs have hospital rooms exposed to abundant daylight and therefore to sunlight, while $3(25 \%)$ do not, while on the other hand, 8 (66\%) of the 12 DTCs laboratories have good natural ventilation and 4(33\%) do not have access to sunlight or sufficient passage of outside air. Half (6/12) of DTCs have table ventilators for nurses' and doctors' offices in order to allow the dilution of the bacillary concentration. In 11 DTCs, health workers collect sputum externally, while in one DTC they do so directly in the laboratory. In 8 (66.67\%) DTCs, waste disposal is correctly done and takes place according to a well-established waste management plan, while 4/12(33\%) do not eliminate them correctly. All DTCs have and use bins containing plastic bags. No DTC has a certified quality biosafety cabinet to ensure safe handling and prevent TB among healthcare workers. Eighty three per cent (10/12) of DTCs use a decontamination solution for equipment made mostly of chlorine and changed every 24 hours. Seventeen per cent (2/12) of DTCs do not use an adequate decontamination solution.

In 11 DTCs, that is $92 \%$, the staff sterilize all the hardware instruments after use, using the autoclave for some and / or oven for others. In a DTC, staff do not sterilize equipment after use and sometimes leave it in the decontamination solution for hours. Equally, in 11/12 (92\%) DTCs, the disinfection of work surfaces is carried 
out using tuberculoicidal products such as chlorine. Eighty three per cent (10/12) of DTCs have protocols related to sensitizing staff on preventive measures against TB through picture boxes and posters for others (Table II).

Table 2 Environmental control measures in DCTs in Douala

\begin{tabular}{lcc}
\hline \multicolumn{1}{c}{ Environmental control measures } & $\begin{array}{c}\text { Frequency } \\
(\mathrm{n}=12)\end{array}$ & Percentage \\
\hline Presence and use of bins containing plastic bags & 12 & 100 \\
Disinfection of work surfaces using a product such as ethanol & 11 & 91.67 \\
Sterilization of all care instruments after use & 11 & 91.67 \\
Sputum collection outside & 11 & 91.67 \\
Presence of protocols relating to staff awareness of preventive measures & 10 & 83.33 \\
Presence and use of a material decontamination solution & 10 & 83.33 \\
Cough hygiene & 10 & 83.33 \\
Abundant exposure of the hospital room to daylight & 9 & 75.00 \\
Correct disposal of infectious material & 8 & 66.67 \\
Good natural ventilation of the laboratory & 8 & 66.67 \\
Presence of table fans for nurses and doctor's offices & 6 & 50.00 \\
Regular ventilation of the hospital room by opening doors and windows & 6 & 50.00 \\
Presence and use of a certified quality biosafety cabinet & & \\
Mean & 0 & 0.00 \\
\hline
\end{tabular}

\section{Protective measures by health care workers in the DCTs}

Of the 12 DCTs evaluated, only in 2(17\%) health workers correctly wear particulate respirators, specifically Filtering Face Piece 2 (FFP2) and N95. Ten (83\%) of the 12 DTCs do not have one due to shortage in their stock as a result of the Covid-19 pandemic. It was observed the washing and / or reuse of respiratory protection masks in 3 DTCs and the glaring breakdown of protective masks in most DTCs or the use of home-made masks in some others. In 10 (83\%) DTCs, health workers use surgical masks as preventive measure form TB infection. Only 2 (27\%) DTCs do not use it. In 7 (58\%) DTCs, the health workers have a good attitude within the laboratory, while in the others, the personnel either eats or make phone calls inside the laboratory. In 11(92\%) of DTCs, healthcare personnel exclusively wear coats with long sleeves in the microbiology laboratory. In 9 (75\%) DTCs, health workers wash their hands with soap before and after work or use hydroalcoholic gels to disinfect their hands. In $9(75 \%)$ DTCs, staff frequently wear single-use care gloves. In the other 3 DTCs, they reuse the same pair of gloves after several days. Seventeen per cent (2/12) of DTCs have health workers presenting atypical signs of TB such as cough (Figure 1). 


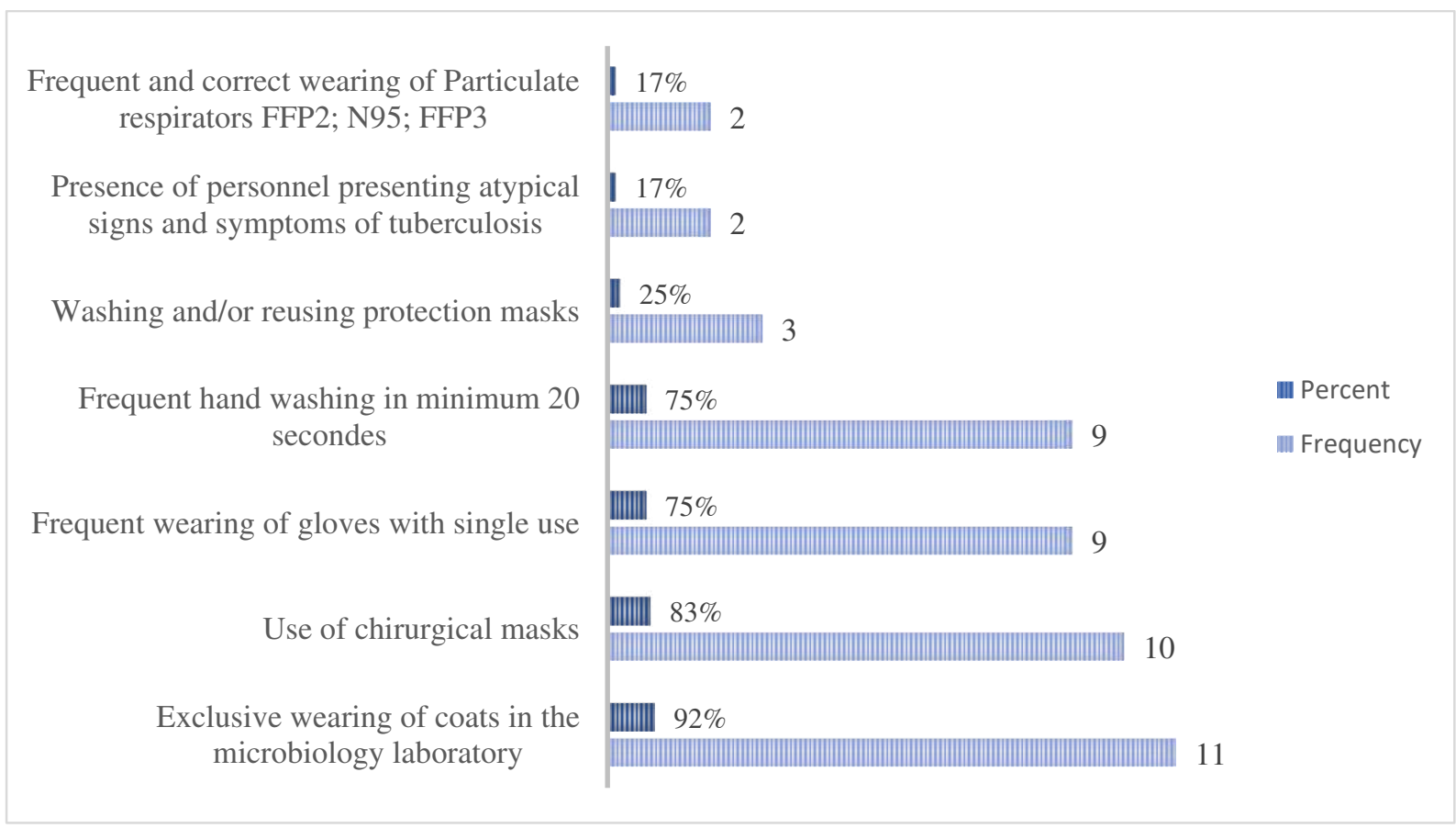

FFP2: Filtering Face Piece 2; FFP3: Filtering Face Piece 3; DTCs: Diagnostic and Treatment Centre for Tuberculosis

Figure 1 Individual protective measures by personnel in the DCTs

\section{Discussion}

Our study focusing the adherence to preventive measures against TB by the health workers in the DTCs of Douala, is in line with other studies carried out by several authors [12, 13, 14], aiming to assess the implementation of administrative, environmental and respiratory protection control measures against TB infection. Our results corroborate with the studies carried out in Japan [12], Portugal [13] and Colombia [14]. The World Health Organization (WHO) guidelines [15], the Center for Disease Control and Prevention (CDC) [16] and Cameroon [11] have proposed the implementation of measures to control TB infection at three levels: administrative, environmental and personal respiratory protection. In the Infection Prevention Control (IPC) TB strategy, administrative controls are the cornerstone and first priority, while the other two are entirely dependent on administrative control for their effectiveness [17].

\section{Administrative control measures}

According to the results of our study, half of the DTCs separate the suspected or confirmed cases of other patients which is in line with a study conducted in Mongolia in 2011 in which 23\% of health facilities separated patients suspected of TB [18]. Equally, one study showed that less than half (46\%) of designated TB hospitals had a separate waiting area for patients. When TB patients and other facility users share the same overcrowded and poorly ventilated waiting area, unnecessarily long waiting times in the process of diagnosis and treatment can increase nosocomial transmission of TB [19]. In a study carried out in Uganda, it was also found that patients who were coughing were not prioritized for outpatient services in over $90 \%$ of facilities. They were observed waiting in the same area with other patients for long hours in queues [20]. The staff therefore said to this effect: "It is 
impossible here [the separation of patients] because we do not have enough space. We don't have a place to put them [the TB suspected cases]". However, a study in South Africa found that 26 facilities (63.4\%) reported separating coughing and non-coughing patients, while observations revealed that only 11 facilities $(26.8 \%)$ had separate waiting zones for TB patients (presumed) [21]. Also in South Africa, a study in 2015 revealed that no establishment in Ugu district had reported separating patients suspected of having TB from other patients [22]. All DTCs notified diagnosed TB cases through health information system data collection tools such as laboratory registers and / or TB registers. This percentage is contrary to that obtained in a study carried out in China in which the results are generally kept by individual workers rather than the employer, especially in small hospitals. Also, negative results are often not recorded. Moreover, these recordings are generally not systematically reported to the national TB control program (NTP) or to the occupational health authorities [23]. According to a study carried out in China, the implementation of TB infection control and reporting of TB cases are both fragmented, due to the wide margin of appreciation enjoyed by Chinese hospitals and local organizations [24]. The mean adhesion to Administrative measures by the health workers of the DTCs was $79.16 \%$. This is contrary to a South African study in which the levels of implementation of administrative measures for TB were less than $20.0 \%$. This is a huge pitfall, as these measures should be implemented from the first contact with a patient in a healthcare facility. Delays in screening, diagnosis and treatment for TB due to failure to implement these checks increase the risk of health care-related illnesses. Administrative measures for the control of TB infection should be the first pillar and should be given greater recognition in the context of the study setting. In the absence of appropriate infection control practices, healthcare associated infections will inevitably remain a risk [17].

\section{Environmental control measures}

Environmental control measures (second priority) depend on the design of infrastructure, use of ventilation and irradiation, all of which require capital investment. However, effective methods have been proposed based on ventilation through window openings [17]. According to our study, half of the DTCs have regularly ventilated hospital rooms through the opening of doors and windows. The other half have hospital wards without windows for some, or with closed doors for others. This ties with a study carried out by Bhebhe who reported that in Lesotho it is difficult to open doors and windows because the weather conditions are harsh, with winters that can record temperatures below $0^{\circ} \mathrm{C}$. This could possibly contribute to the fact that some healthcare workers cannot open windows and doors for ventilation [17]. These external climatic conditions, as well as the individual perceptions of the workers concerning the cold or the heat and opening of the various services (medical and surgical unit) were mentioned in a study carried out in Colombia [14]. Natural ventilation, such as through windows and open doors, is efficient and less expensive for air circulation as shown in up to $67 \%$ of DTCs laboratories in our study with good natural ventilation which corroborates a Chinese study in which the natural ventilation of TB services was observed in $89 \%$ of hospitals [19]. Nonetheless, 33\% of DTCs in our study do not have access to sunlight or sufficient passage of outdoor air. Ventilation is a vital measure of environmental control. Although natural and mechanical ventilation methods were present in most of the hospitals designated for TB in the present study, regular monitoring of ventilation (at least quarterly) for the control of TB infection was carried out in only $57 \%$ of hospitals surveyed, indicating that many did not sufficiently cater for maintenance, thereby increasing the risk of healthcare workers to infection. [19]. These figures are in line with those from a study carried out by Buregyeya et al. (2013) in which only $32 \%$ had in their facilities, available windows that were completely open [20]. In 11 
DTCs, health workers collect sputum externally, while only one DTC does so directly in the laboratory. This is in line with a study in which $6 \%$ of hospitals took sputum samples outside the hospital building [19]. In addition, WHO guidelines recommend that sputum collection be done outdoors, away from other people or in wellventilated areas [15]. The majority (87\%) of DTCs in our study use a solution for decontamination of equipment made mostly of chlorine and changed every 24 hours, which corroborates with the results of a Chinese study in which $96 \%$ of hospitals disinfect the sputum collection area and medical equipment daily [19].

\section{Individual protection measures}

Personal respiratory protection is the third and final recommended barrier to protect healthcare workers against inhalation of infectious droplets [11]. In $17 \%$ of DTCs, health workers correctly wear particulate respirators precisely FFP2 and N95, which have an efficiency of 95\% minimum filtration for particles of 0.3 micron in diameter [12]. Eighty-three percent of DTCs do not have one due to shortage in stock as a result to the Covid-19 pandemic. A study carried out in South Africa showed that only $38.8 \%$ of the staff used the N95 breathing apparatus [17]. The unavailability of respiratory protective equipment could limit their use in hospital. Several other studies have shown that very few health workers regularly wear personal respirators when evaluating patients for TB as in China [23], or South Africa with a percentage use of masks of 22\% in hospitals by staff [25]. The result of our study also corroborates with another in South Africa in which $40 \%$ of hospital facilities lacked masks and disposable respirators [22]; as well as that of Malangu still in South Africa where only 22\% clinics had N95 masks available for staff [21]. In the same line, a study in Brazil indicated that adherence to the use of the N95 mask is not very well established among healthcare professionals, resulting in low compliance [26]. Thus, according to a study in Russia, the quality of the N95 mask, the discomfort and the neglect of its importance are factors of non-adherence to its use [27]. However, other studies are in contrast to the previous ones evoking the availability of protective masks such as that of Sousa in Portugal in which the health workers used protective respiratory equipment (92\%) [13] and Chen where most (97\%) hospitals provided N95 respirators for health workers [19]. Our study shows that in most DTCs, healthcare workers use surgical masks for the prevention of TB that do not filter the nuclei of infectious droplets [14]. This result is in line with a study carried out in Colombia in which the institution was permanently making surgical masks available to the health workers for their protection [14]. Also in Uganda, health workers wore only surgical masks for protection [20]. In $92 \%$ of DTCs, health workers exclusively wear coats with long sleeves in the microbiology laboratory which is contrary to of a study carried out recently in South Africa where only $19 \%$ of the staff wore recommended coats [25]. In 17\% of the DTCs, the health workers present atypical signs of TB such as cough. This is certainly due to the lack of screening among health workers and corroborates with a study carried out in Japan in which many establishments did not verify the presence of fever and / or respiratory symptoms [12]. No DTC screen either annually or twice yearly their staff for TB. Also, the training of health workers in the fight against TB infection is not effective in these DTCs. This is inconsistent with Chen's study in which $92 \%$ hospitals offered TB infection control training, $74 \%$ screened staff for TB at least once per year and $69 \%$ tested staff's knowledge about infection control each year [19]. 


\section{Conclusion}

Implementation of TB preventive measures (administrative, environmental and personal) by health staff in the centers for screening and treatment of TB in the city of Douala is insufficient with respective average of $79.16 \%$ for management measures, $71.80 \%$ for environmental measures and $54.76 \%$ for individual protective measures. It is in this light that their implementation must be strengthened, especially the separation of patients suspected of TB and confirmed TB patients, selection and priority service to shorten the stay of TB patients and regular monitoring and control of TB infection through screening and training of health workers on strict compliance to prescribed measures. DTCs with lower admission rates of TB patients should also place more emphasis on infection control measures such as collecting sputum outdoors and using appropriate respirators such as FFP2 or even the N95. Also, other research methods such as quantitative measurement of adequacy of ventilation, a study of the prevalence of latent TB among health workers through molecular biology techniques and in-depth interviews with the health workers could be conducted to assess the effectiveness of measures to control TB infection. Limited resources such as funds, space, and lack of appreciation on the importance of TB have prevented even simple, inexpensive, and most important TB infection control (TBIC) interventions from being adopted. Therefore, to ensure the implementation of recommended TBIC practices, full support beyond training (for example, human resources, provision of masks, space and other modifications, supportive supervision and practical support in developing and implementing TBIC plans) are important. Limited infection control practices exist in DTCs in the high TB burden city of Douala, Cameroon. This study thus highlights the shortcomings and paved the way for an improvement in the implementation of preventive measures against TB infection through the adoption of specific recommendations based on the gaps observed in the diagnostic and treatment centers of the city of Douala.

\section{Abbreviations}

AIDS: Acquired Immunodeficiency Syndrome; DTC: Diagnostic and Treatment Centre for Tuberculosis; FFP2: Filtering Face Piece 2; FFP3: Filtering Face Piece 3; IC: Infection Control; IPC: Infection Prevention Control; WHO: World Health Organization; TB: Tuberculosis; TBIC: Tuberculosis infection control; HIV: Human Immunodeficiency Virus.

\section{Declarations}

\section{Ethical approval and consent to participate}

This study was approved by the institutional ethical committee of the University of Douala, located in the city where the study was carried out. Also, research authorizations were obtained from the Regional Technical Group for Tuberculosis in the Littoral region and the various officials of the Tuberculosis Diagnostic and Treatment Centers in Douala. Informed consent of all participants was obtained. All methods were performed in accordance with the relevant guidelines and regulations/declaration of Helsinki.

\section{Consent for publication}

Not applicable 


\section{Availability of data and material}

All data is available on request (B.Thumamo Pokam - thumamo@yahoo.fr).

\section{Competing interest}

The authors declare no conflict of interest.

\section{Funding}

NGO Prevention and Control supported this research work.

\section{Authors contributions}

CID conceived and coordinated the study. ASNN gathered the literature and wrote the manuscript. ASNN, IGW, WDYT, FWNK, AK, AMA, and ET collected the data. CID and BDTP supervised and substantially revised the manuscript. All authors read and approved the final version of the manuscript.

\section{Acknowledgments}

Our sincere thanks go to all those who have participated directly or indirectly in the elaboration of this work; precisely the health workers of the 12 tuberculosis diagnostic and treatment centers in the city of Douala for their kind assistance and their dedication to this research.

\section{Authors' information}

1Université des Montagnes, Bagangte, Cameroon. 2Department of Health and Applied Sciences, Estuary Academic and Strategic Institute, Cameroon. 3Regional Delegation of Public Health Littoral region, Regional Technical Group for the Fight against Tuberculosis Littoral region, Cameroon. 4Prevention and Control Foundation, Cameroon. 5HIV / AIDS sub-Directorate, Ministry of Public Health, Cameroon. 6Department of Medical Laboratory Science, Faculty of Health Sciences, University of Buea, Cameroon.

Authors

\author{
Cecile I. Djuikoue
}

Alex S. Ndjip Ndjock

Irene G. Wandji

Willy D. Yamdeu Tchoukouha

Frank W. Nounkeu Kouteu

Alice Ketchaji

Ashu M. Agbor

Ernest Tambo

Benjamin D. Thumamo Pokam

\section{Adresses}

djuikoe1983@yahoo.fr alexndjock@gmail.com adywandji@gmail.com yamdeuwilly@gmail.com wnounkeufrank@yahoo.com ketchajialice2015@gmail.com agborasm@gmail.com> tambo0711@gmail.com thumamo@yahoo.fr 


\section{References}

1. WHO 2020, Tuberculosis, Fact sheets. https://www.who.int/fr/news-room/factsheets/detail/tuberculosis. Accessed 11 Nov 2020. WHO, Geneva, Switzerland

2. WHO. Global tuberculosis control: epidemiology, strategy, financing: WHO Report 2017. WHO; Geneva, Switzerland. 2018.

3. De Laroche M, Abiteboul D, Aubier M, Lolom I, Pellissier G, Rouveix E. Tuberculose et personnel soignant : prévention du risque en milieu de soins (2020)

4. Kumar MG, Joseph B, Goud BR, Joseph M, Rajitha M. Risk of Tuberculosis Infection among Healthcare Workers in a Tertiary Care Hospital in Bengaluru City (2019)

5. Gehanno J-F, Abiteboul D, Rollin L. Incidence of tuberculosis among nurses and healthcare assistants in France (2017)

6. Simo Epse Nenwouo L, Pefura Yone E, Fatime Abaicho H, Enono Edende P. Épidémiologie et issue de traitement de la tuberculose de l'enfant à Yaoundé, Cameroun (2016)

7. Francis BOGNI. Analyse du système d'information de lutte contre la tuberculose au Cameroun. https://www.memoireonline.com/08/11/4645/m_Analyse-du-France-dinformation-de-lutte-contre-latuberculose-au-Cameroun0.html. Accessed 15 juin 2020.

8. Donkou FR. devenir des enfants traités pour tuberculose dans la région du nord Cameroun (2018)

9. Prise en charge des patients souffrant de la tuberculose en milieu urbain : offre de soins et parcours thérapeutique (2013)

10. Noubom M, Nembot FD, Donfack H, Mfin PSK, Tchasse F. Caractéristiques des patients tuberculeux à l'ouest cameroun : 2000-2009 (2013)

11. Guide technique pour les personnels de santé du Cameroun. : 190.

12. Suzuki Y, Sone T. [A study on preventive measures against tuberculosis in care facilities for the elderly in a Tokyo metropolitan district] (2011)

13. Nosocomial tuberculosis prevention in Portuguese hospitals: a cross-sectional evaluation (2012)

14. Castro-cely Y. Medidas de control de tuberculosis en una institución de salud de Bogotá D. C Control measures against tuberculosis in a health care providing (2016)

15. World Health Organization. Guidelines for the prevention of tuberculosis in healthcare facilities in resource-limited settings. Geneva, Switzerland. WHO, 2005.

16. Centre for Disease Control and Prevention. Guidelines for preventing the transmission of Mycobacterium tuberculosis in health-care settings, 2005.

17. Bhebhe LT, Van Rooyen C, Steinberg WJ. Attitudes, knowledge and practices of healthcare workers regarding occupational exposure of pulmonary tuberculosis (2014)

18. Weimin Z, Feng H, Haidong W et al. 2011. The implementation of "Handbook of Chinese control and prevention of TB infection', in four healthcare facilities (2011)

19. Chen B, Liu M, Gu H, Wang X, Qiu W, Shen J, et al. Implementation of tuberculosis infection control measures in designated hospitals in Zhejiang Province, China: are we doing enough to prevent nosocomial tuberculosis infections? (2016) 
20. Buregyeya E, Nuwaha F, Verver S, Criel B, Colebunders R, Wanyenze R, et al. Implementation of tuberculosis control in health facilities in Mukono and Wakiso districts in Uganda (2013)

21. Malangu N, Mngomezulu M. Evaluation of tuberculosis infection control measures implemented at primary health care facilities in Kwazulu-Natal province of South Africa (2015)

22. Engelbrecht MC, Kigozi G, Janse van Rensburg AP, Van Rensburg DHCJ. Tuberculosis infection control practices in a high-burden metro in South Africa: A perpetual bane for efficient primary health care service delivery (2018)

23. Chai SJ, Mattingly DC, Varma JK. Protecting health care workers from tuberculosis in China: a review of policy and practice in China and the United States. Health Policy Plan (2013)

24. He GX, Van Den Hof S, Van Der Werf MJ et al. 2010. Infection control and the burden of tuberculosis infection and disease in health care workers in China: a cross-sectional study (2010)

25. Ndlebe L, Williams M, ten Ham-Baloyi W, Venter D. Employees' knowledge and practices on occupational exposure to tuberculosis at specialised tuberculosis hospitals in South Africa (2020)

26. Eni Hilário da Silva. Evaluation of occupational tuberculosis prevention in a brazilian hospital Avaliação da prevenção de tuberculose ocupacional em um hospital brasileiro, pp. 549-56 (2015)

27. Woith W, Volchenkov G, Larson J. Barriers and motivators affecting tuberculosis infection control practices of Russian heath care workers (2012) 


\section{Figures}

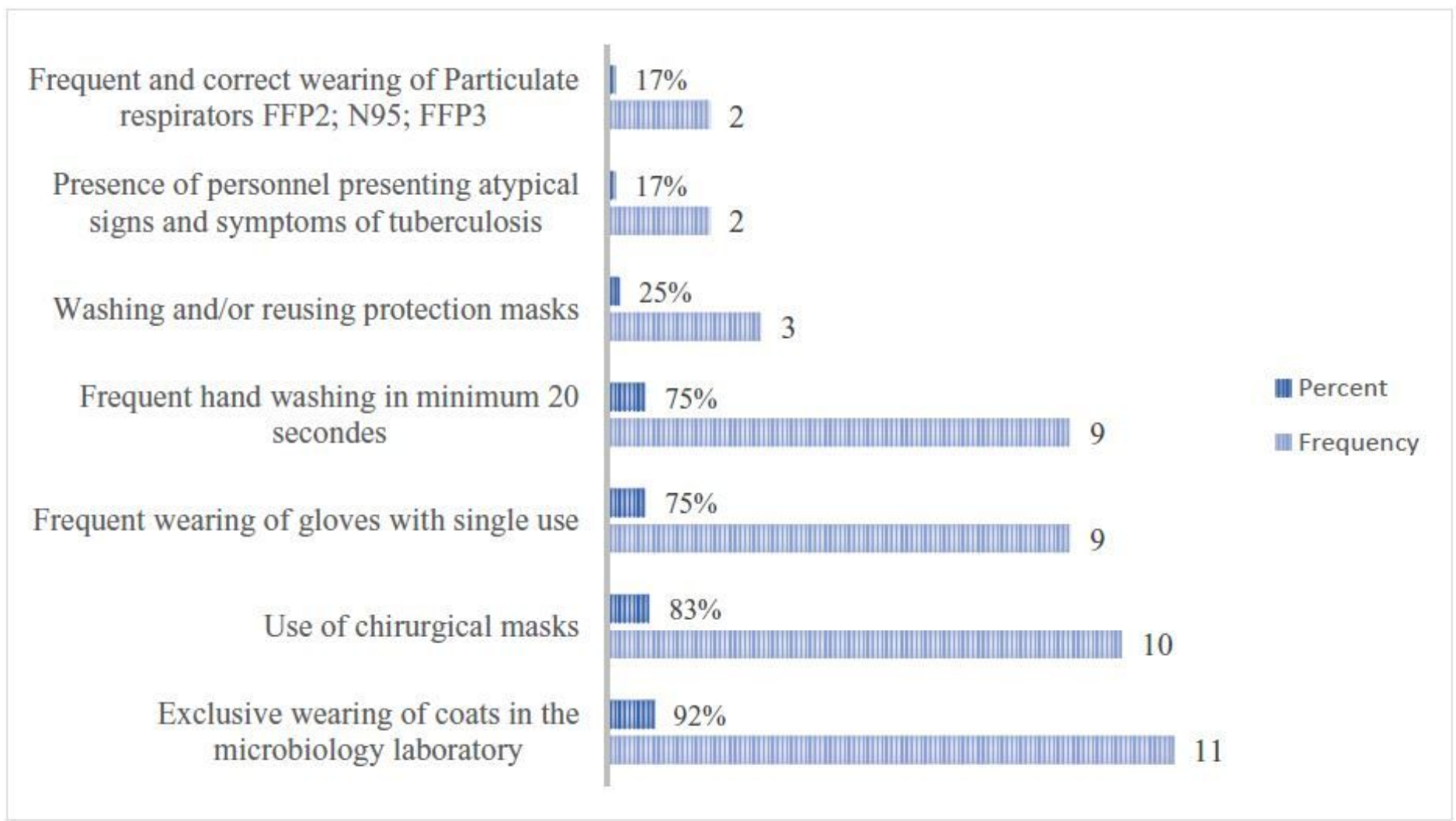

\section{Figure 1}

Individual protective measures by personnel in the DCTs. FFP2: Filtering Face Piece 2; FFP3: Filtering Face Piece 3; DTCs: Diagnostic and Treatment Centre for Tuberculosis. 